\title{
Improving Travels of the Public Transport System of Guadalajara Using ACO
}

\author{
Edgar Gonzalo Cossio Franco ${ }^{1}$, José Alberto Hernández Aguilar², \\ Alberto Ochoa-Zezzatti ${ }^{3}$, Julio César Ponce Gallegos ${ }^{4}$ \\ ${ }^{1}$ Universidad Da Vinci/Universidad Enrique Díaz de León, Mexico \\ ${ }^{2}$ Universidad Autónoma del Estado de Morelos, Mexico \\ ${ }^{3}$ Universidad Autónoma de Ciudad Juárez, Mexico \\ ${ }^{4}$ Universidad Autónoma de Aguascalientes, Mexico \\ kofrran@gmail.com, alberto_doctor@hotmail.com, alberto.ochoa@uacj.mx, \\ julk_cpg@hotmail.com
}

\begin{abstract}
This paper presents the application of ant algorithm to improve public transport route in the metropolitan area of Guadalajara. We use a methodology with an eight-step sequence in which it is possible to: 1 . Identify the problem, 2. Identify the sources of information, 3. Prepare the census to collect the data. 4. Raise the information, 5. Analyze the data, 6. Treat the information, 7. Implement the algorithm and 8. Analyze the results. We use a methodology with an eight-step sequence in which it is possible to: 1 . Identify the problem, 2. Identify the sources of information, 3. Prepare the census to collect the data. 4. Raise the information, 5. Analyze the data, 6 . Treat the information, 7. Implement the algorithm and 8 . Analyze the results. The contribution is to improve the routing Public transport in the ZMG through the implementation of Bio-inspired algorithms that will shorten the distance and the time of Travel from origin to destination.
\end{abstract}

Keywords: C++, Instances, Traffic, Ant Colony Optimization.

\section{Introduction}

In the last population census of 2010, conducted by the INEGI, identified in the area of mobility growth rates in terms of vehicle fleet it has been increasing: the rate of motorcycles increased by $30 \%$ annually between 1990 and 2010, from 16,000 to 177,000. In the same period, the rate grew to $7.31 \%$ cars, and trucks and cargo vans to $7.66 \%$. The lower rate is that of passenger buses $-3.49 \%$ - certainly closer to the growth of housing in the state. ZMG concentrated two-thirds of the vehicle fleet with $65 \%$. 


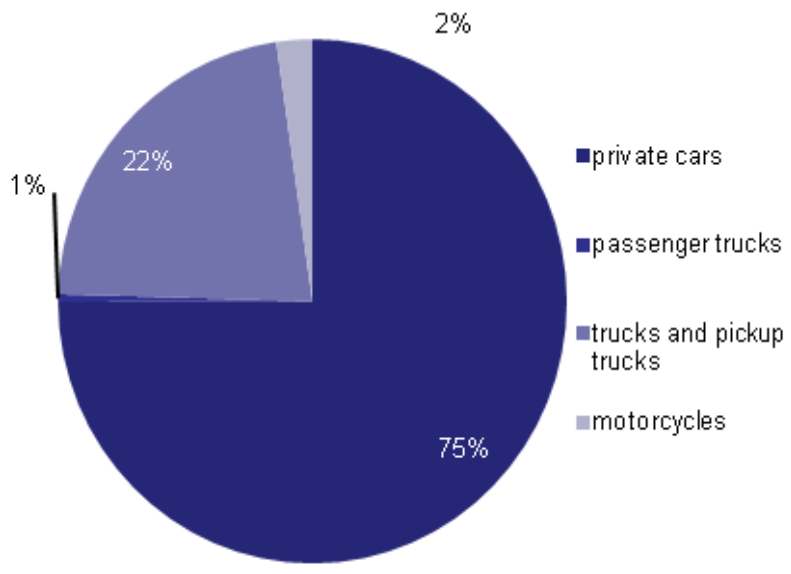

Fig. 1. ZMG Vehicle fleet [1].

In the figure above 4 types of transport are shown. It is identified as the predominant percentage use of private cars and the least dominant is represented by passenger trucks [1].

A bio-inspired algorithm based on ant colony is proposed for the optimization of the routing problem.

According to the literature reviewed, the following elements were found:

- Application of ant algorithm

The ant algorithm is a powerful implementation to solve complex problems; is based on the application of heuristics and probability for decision making [2].

It is possible to use ACO to estimate the traffic flow paths, as established in [3], where the application is shown to a specific case of Havana.

ACO is used in pharmaceutical industry to analyzing proteins for the study of AIDS [4].

Various routing optimization systems can be found in the market using bio-inspired algorithms, among which the following can be found:

\section{- SOSACO}

It is a search engine for social networks. The algorithm identifies new paths easier without breaking the original graphs [5]. This intelligence is useful in the application of GPS systems and in the precision they offer [6].

\section{- MIDACO}

Mixed Integer Distributed Ant Colony Optimization is an innovative optimization software for continuous and combinatorial problems. A special feature of MIDACO is its parallelization capability. The MIDACO parallelization option is based on the concept of reverse communication and can be used in all common distributed computing support 
architectures (including HPC and GPU). This function aims to parallel the evaluation (expensive CPU time) of the objective functions and constraints. It is designed for time consuming applications, where a single evaluation requires seconds, minutes or even hours [7].

- Vehicle routing problem

The original assumption of VRP is the problem of vehicle routes of a city; the problem is in the distribution of routes, times and load for each unit. The goal is to achieve [8]:

- that all nodes are visited exactly by a vehicle once,

- that all routes begin and end at a depot,

- For each unit, the load does not exceed the capacity of vehicles,

- For each unit, the distance does not exceed the given limit.

VRP extends its variants to suit different road problems [9]:

- CVRP (Capacitated Vehicle Routing Problem)

The units have uniform capacity and must meet customer demands known for a single product from a common warehouse at a minimum cost of transit. That is, CVRP is like VRP with the additional limitation that each unit must equal the uniform capacity of a single product.

- VRPTW (Vehicle Routing Problem with Time Windows)

Each of the clients, as well as the deposit, has several time windows of delivery or delivery [10].

\section{General Objective}

In Jalisco the number of vehicles has grown over the last thirty years by $7.29 \%$ per year, this amount is above the percentages of population and housing; motorcycles have $30 \%$, cars with $7.66 \%$ and finally public transportation with $3.49 \%$.

The ZMG contains two-thirds of total vehicles with $65 \%$ [11]. One of the main problems, when talking about mobility in public transport, is the time it takes to reach a unit from the origin to the destination, caused by ignorance of the route, inaccessibility to roads, climate issues, traffic load (peak hour / hour valley).

Our goal is to implement ACO to a problem of public transport in the metropolitan area of Guadalajara with the aim of improving travel.

\section{$3 \quad$ Process}

As defined at the beginning of the present study, the proposed methodology is composed of eight stages which are shown in the Figure 2. 


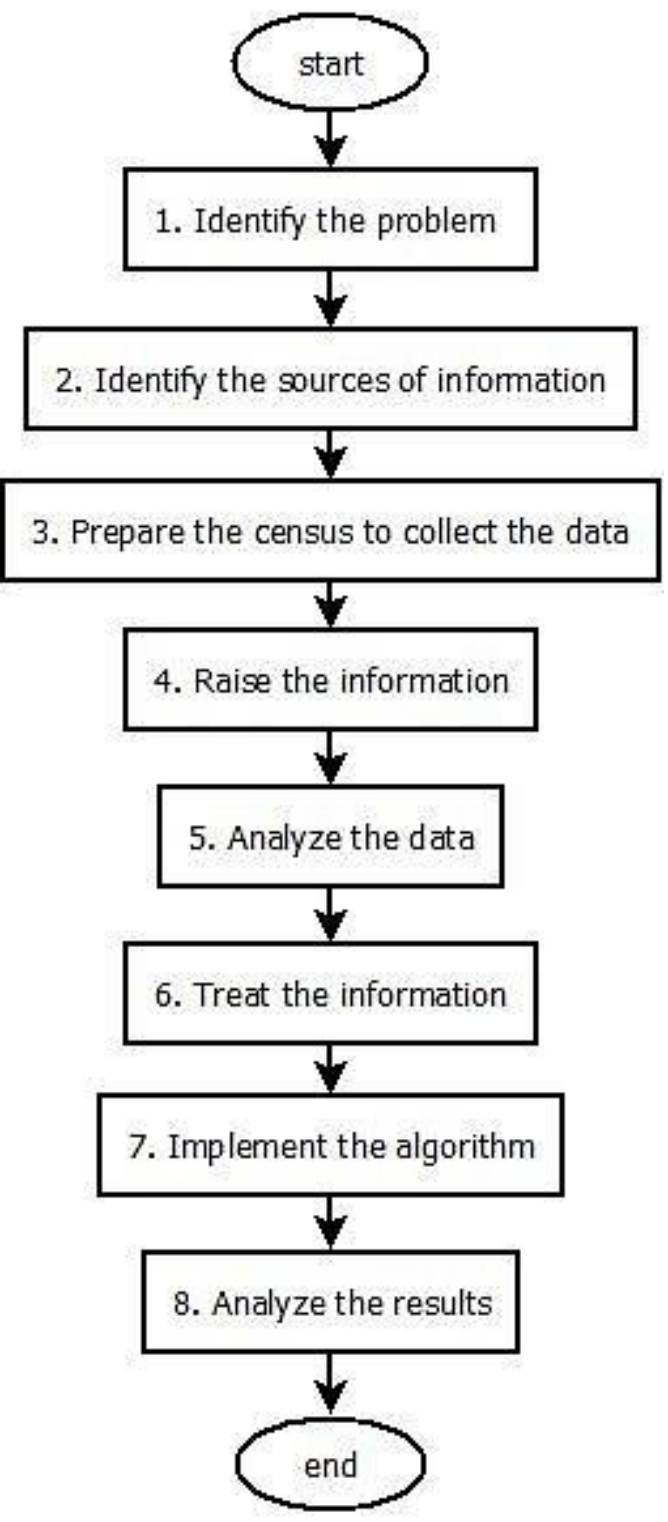

Fig. 2. Process.

The total distance is calculated, the number of routes for each execution and the number of vehicles, with the inputs 25 cities (nodes). 


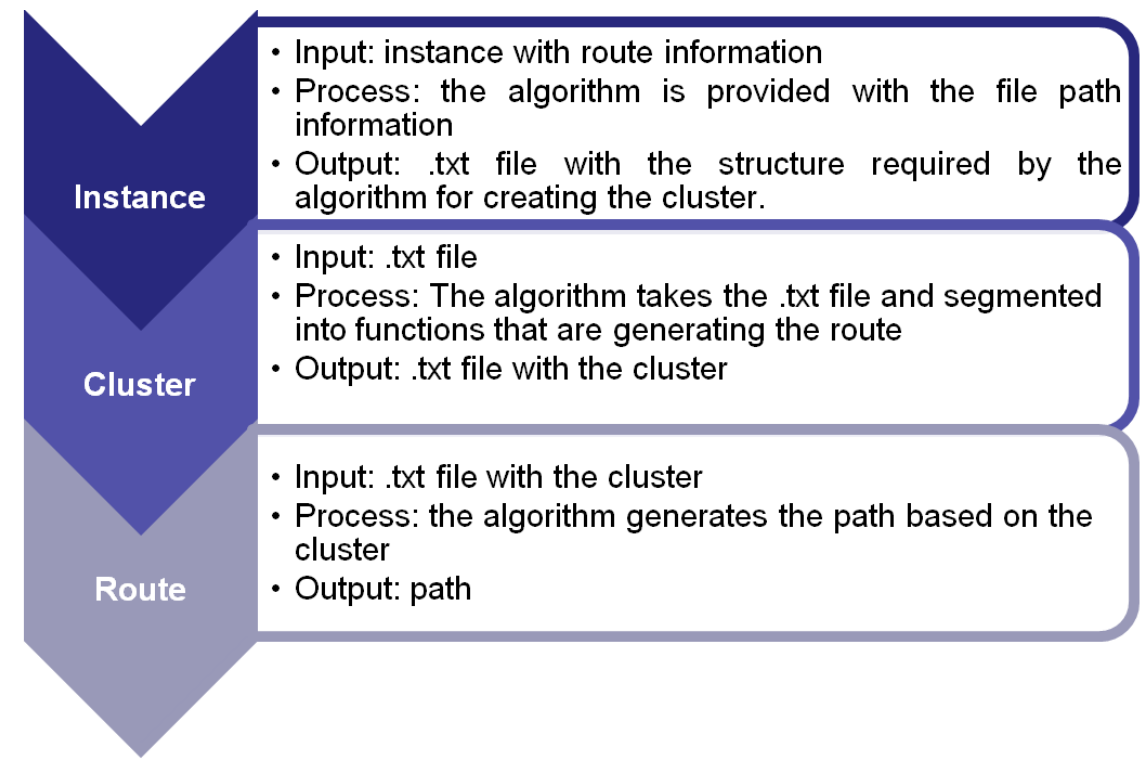

Fig. 3. Stages of processing.

The process consists of three elements; an instance as input, clusters are created and finally the route is created.

\section{Experiment}

The complete path consists of the following data:

The following data is used in the experiment:

- 33 units,

- 71 drivers,

- 37 points,

- Daily average per unit:

- Passengers: 528,

- Laps: 4,

- Time of turns: 50 minutes.

The experiment consists of:

1 Identify points along the route. 
Table 1. Control points.

\begin{tabular}{|c|c|c|c|c|c|c|c|c|c|c|c|c|c|}
\hline trip & number & punto & lat & long & $\mathrm{x}$ & Y & trip & number & punto & lat & long & $\mathrm{x}$ & $\mathrm{Y}$ \\
\hline \multirow{20}{*}{ g } & 1 & Base 214 & 20.63128 & -103.272 & 95 & 73 & \multirow{20}{*}{$\begin{array}{l}r \\
\text { e } \\
\text { t } \\
\text { u }\end{array}$} & 1 & contestación & 20.62345 & 103.3999 & 6 & 84 \\
\hline & 2 & Farm GDL & 20.63564 & -103.276 & 92 & 68 & & 2 & Zansibar-Imss & 20.62631 & -103. & 11 & 82 \\
\hline & 3 & Rio Nilo & 20.63904 & -103.277 & 92 & 63 & & 3 & Reyes Heroles & 20.62875 & -103.391 & 12 & 77 \\
\hline & 4 & Curva Malecon & 20.64367 & -103.278 & 92 & 56 & & & (2) & 20.02010 & & & \\
\hline & 5 & Templo Malecón & 20.64762 & -103.274 & 94 & 50 & & 4 & Isla Gomer & 20.6368 & -103.392 & 11 & 66 \\
\hline & 6 & Pizzería 61 & 20.65312 & -103.28 & 90 & 43 & & 5 & $\begin{array}{l}\text { Retorno } 61 \\
\end{array}$ & 20.65792 & -103.377 & 20 & 36 \\
\hline & 7 & Bolería & 20.6552 & -103.294 & 80 & 40 & & 6 & & 20.66463 & -103.364 & 32 & 33 \\
\hline & 8 & Ramón Val-Pensador & 20.65748 & -103.309 & 70 & 37 & & 7 & Paztolsa & 20.66651 & -103.359 & 34 & 26 \\
\hline & 9 & Arena Jalisco & 20.66469 & -103.317 & 64 & 26 & & 8 & Pque. Sn. Fco. & 20.67286 & $-103.34 \pi$ & 44 & 22 \\
\hline & 10 & Cuartel colorado & 20.67049 & -103.334 & 52 & 18 & & & & & & & \\
\hline & 11 & Zapatería prado & 20.67298 & $\mid-103.342$ & 46 & 15 & & 9 & Med 56 & 20.67099 & $\mid 103.341$ & 48 & 25 \\
\hline & 12 & Pque. Sn. Fco. & 20.67357 & -103.348 & 42 & 14 & & 10 & Cv Ruiz Sanchez & 20.66268 & -103.32 & 63 & 37 \\
\hline & 13 & 8 de julio-la paz & 20.67216 & -103.353 & 38 & 16 & & 11 & Vinos la playa & 20.65814 & -103.308 & 72 & 42 \\
\hline & 14 & Paztolsa & 20.66566 & -103.36 & 34 & 26 & & 12 & Mercado Osos & 20.65281 & -103.294 & 82 & 49 \\
\hline & 15 & Lab. Piza & 20.66386 & $-103.365 \mid$ & 30 & 28 & & 13 & Templo Malecón & 20.64762 & -103.274 & 94 & 50 \\
\hline & 16 & Retorno 61 & 20.658 & -103.378 & 20 & 36 & & 14 & & 64169 & -103 & 94 & 65 \\
\hline & 17 & Isla Gomer & 20.63682 & -103.392 & 11 & 66 & & & & & & & \\
\hline & 18 & Reyes Heroles & 20.62875 & $\mid-103.391$ & 12 & 77 & & 15 & Santa Rosalia-Mal & 20.63678 & -103.279 & 93 & 72 \\
\hline & 19 & Zansibar-Imss & 20.62631 & -103.391 & 11 & 82 & & 16 & Farm GDL & 20.63516 & -103.27 & 92 & 68 \\
\hline & 20 & Contestación & 20.62345 & -103.4 & 6 & 84 & & 17 & Base 214 & 20.63128 & -103.272 & 95 & 73 \\
\hline
\end{tabular}

2 Identify the number of passengers moving from one point to another.

Table 2. Instances.

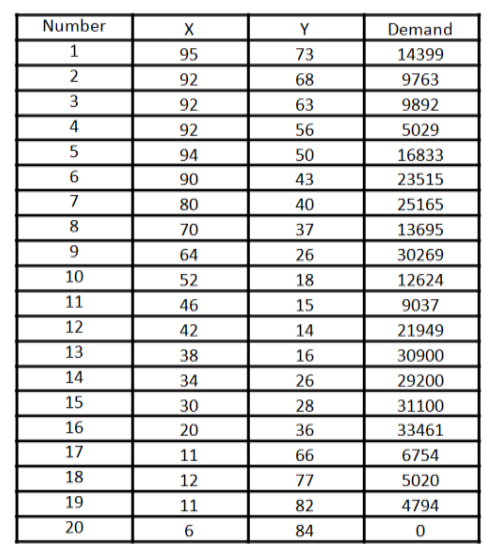

\begin{tabular}{|c|c|c|c|}
\hline Number & $X$ & $Y$ & Demand \\
\hline 21 & 6 & 84 & 0 \\
\hline 22 & 11 & 82 & 45261 \\
\hline 23 & 12 & 77 & 16684 \\
\hline 24 & 11 & 66 & 48247 \\
\hline 25 & 20 & 36 & 147 \\
\hline 26 & 32 & 33 & 59589 \\
\hline 27 & 34 & 26 & 40230 \\
\hline 28 & 44 & 22 & 36416 \\
\hline 29 & 48 & 25 & 20500 \\
\hline 30 & 63 & 37 & 16673 \\
\hline 31 & 72 & 42 & 21461 \\
\hline 32 & 82 & 49 & 10546 \\
\hline 33 & 94 & 50 & 16833 \\
\hline 34 & 94 & 65 & 10300 \\
\hline 35 & 93 & 72 & 7200 \\
\hline 36 & 92 & 68 & 928 \\
\hline 37 & 95 & 73 & 0 \\
\hline
\end{tabular}

For the experiment, three factors were selected: Shifts, Units and Days to determine the route. The turns are identified in three moments: $\mathrm{M}, \mathrm{T}$ and $\mathrm{N}$ where $\mathrm{M}=$ Morning ( 8 a.m.), $\mathrm{T}=$ Late (12 p.m.) and $\mathrm{N}=$ Night (6 p.m.).

The selection of the shifts seeks to identify which route is the most demanded and in which shift. Three units (r5, r12 and r23) are analyzed. Finally we consider the days of the 
week from Monday to Friday (d1, d2, d3, d4 and d5) where d1 = Monday, d2 = Tuesday, $\mathrm{d} 3=$ Wednesday, $\mathrm{d} 4=$ Thursday and $\mathrm{d} 5=$ Friday.

The Figure 4 shows the analysis mentioned.

\begin{tabular}{|l|}
\hline Turn \\
\hline $\mathrm{M}=8$ a.m. \\
\hline $\mathrm{T}=12$ p.m. \\
\hline $\mathrm{N}=6$ p.m. \\
\hline $\mathrm{r} 5$ \\
\hline $\mathrm{r} 12$ \\
\hline $\mathrm{r} 23$ \\
\hline
\end{tabular}

\begin{tabular}{|l|}
\hline Day \\
\hline $\mathrm{d} 1$ = Monday \\
\hline $\mathrm{d} 2=$ Tuesday \\
\hline $\mathrm{d} 3=$ Wednesday \\
\hline $\mathrm{d} 4$ = Thursday \\
\hline $\mathrm{d} 5=$ Friday \\
\hline
\end{tabular}

Fig. 4. Factors for analysis.

The next step is to prepare the matrix in Excel with the data for analysis in Statgraphics Centurion XVI. The result is shown in Image 4:

\begin{tabular}{|c|c|c|c|c|c|}
\cline { 2 - 7 } \multicolumn{1}{c|}{} & \multicolumn{5}{c|}{ U5 } \\
\cline { 2 - 6 } \multicolumn{1}{c|}{ d1 } & d2 & d3 & d4 & d5 \\
\hline M & 335 & 288 & 286 & 307 & 285 \\
\hline T & 205 & 294 & 291 & 284 & 149 \\
\hline N & 202 & 128 & 101 & 156 & 178 \\
\hline
\end{tabular}

\begin{tabular}{|c|c|c|c|c|c|}
\cline { 2 - 6 } \multicolumn{1}{c|}{} & \multicolumn{5}{|c|}{ U12 } \\
\cline { 2 - 6 } \multicolumn{1}{c|}{ d1 } & d2 & d3 & d4 & d5 \\
\hline $\mathbf{M}$ & 207 & 32 & 246 & 299 & 292 \\
\hline $\mathbf{T}$ & 84 & 168 & 135 & 113 & 113 \\
\hline $\mathbf{N}$ & 252 & 341 & 246 & 0 & 130 \\
\hline
\end{tabular}

\begin{tabular}{|c|c|c|c|c|c|}
\cline { 2 - 6 } \multicolumn{1}{c|}{} & \multicolumn{5}{|c|}{ U23 } \\
\cline { 2 - 6 } \multicolumn{1}{c|}{} & d1 & d2 & d3 & d4 & d5 \\
\hline $\mathbf{M}$ & 292 & 332 & 286 & 228 & 164 \\
\hline $\mathbf{T}$ & 255 & 295 & 258 & 261 & 205 \\
\hline $\mathbf{N}$ & 207 & 189 & 183 & 164 & 0 \\
\hline
\end{tabular}

Fig. 5. Data for the Matrix.

The data in each table represent the sum of the loads that are defined by time as the case for $\mathrm{M}, \mathrm{T}$ and $\mathrm{N}$.

In total there are 45 records identified by time, unit, day and capacity.

The matrix generated with the above information is shown in Table 3:

Table 3. Result matrix.

\begin{tabular}{|c|c|c|c|}
\hline time & Unit & day & capacity \\
\hline $\mathrm{T}$ & $\mathrm{r} 23$ & 3 & 258 \\
\hline $\mathrm{M}$ & $\mathrm{r} 12$ & 5 & 292 \\
\hline $\mathrm{T}$ & $\mathrm{r} 12$ & 1 & 84 \\
\hline $\mathrm{T}$ & $\mathrm{r} 23$ & 2 & 295 \\
\hline $\mathrm{T}$ & $\mathrm{r} 23$ & 1 & 255 \\
\hline $\mathrm{M}$ & $\mathrm{r} 5$ & 2 & 288 \\
\hline $\mathrm{M}$ & $\mathrm{r} 23$ & 3 & 286 \\
\hline $\mathrm{T}$ & $\mathrm{r} 5$ & 2 & 294 \\
\hline $\mathrm{N}$ & $\mathrm{r} 5$ & 2 & 128 \\
\hline $\mathrm{T}$ & $\mathrm{r} 12$ & 3 & 135 \\
\hline
\end{tabular}




\begin{tabular}{|c|c|c|c|}
\hline $\mathrm{N}$ & $\mathrm{r} 12$ & 4 & 0 \\
\hline $\mathrm{N}$ & $\mathrm{r} 12$ & 3 & 246 \\
\hline $\mathrm{M}$ & $\mathrm{r} 5$ & 4 & 307 \\
\hline $\mathrm{M}$ & $\mathrm{r} 12$ & 3 & 246 \\
\hline $\mathrm{T}$ & $\mathrm{r} 23$ & 5 & 205 \\
\hline $\mathrm{N}$ & $\mathrm{r} 5$ & 4 & 156 \\
\hline $\mathrm{N}$ & $\mathrm{r} 5$ & 3 & 101 \\
\hline $\mathrm{T}$ & $\mathrm{r} 5$ & 1 & 205 \\
\hline $\mathrm{T}$ & $\mathrm{r} 12$ & 5 & 113 \\
\hline $\mathrm{N}$ & $\mathrm{r} 23$ & 2 & 189 \\
\hline $\mathrm{T}$ & $\mathrm{r} 23$ & 4 & 261 \\
\hline $\mathrm{N}$ & $\mathrm{r} 23$ & 5 & 0 \\
\hline $\mathrm{N}$ & $\mathrm{r} 23$ & 1 & 207 \\
\hline $\mathrm{M}$ & $\mathrm{r} 5$ & 3 & 286 \\
\hline $\mathrm{T}$ & $\mathrm{r} 5$ & 5 & 149 \\
\hline $\mathrm{N}$ & $\mathrm{r} 5$ & 5 & 178 \\
\hline $\mathrm{T}$ & $\mathrm{r} 5$ & 3 & 291 \\
\hline $\mathrm{N}$ & $\mathrm{r} 5$ & 1 & 202 \\
\hline $\mathrm{T}$ & $\mathrm{r} 12$ & 4 & 113 \\
\hline $\mathrm{M}$ & $\mathrm{r} 12$ & 1 & 207 \\
\hline $\mathrm{N}$ & $\mathrm{r} 12$ & 5 & 130 \\
\hline $\mathrm{M}$ & $\mathrm{r} 12$ & 4 & 299 \\
\hline $\mathrm{T}$ & $\mathrm{r} 5$ & 4 & 284 \\
\hline $\mathrm{N}$ & $\mathrm{r} 12$ & 1 & 252 \\
\hline $\mathrm{M}$ & $\mathrm{r} 12$ & 2 & 32 \\
\hline $\mathrm{M}$ & $\mathrm{r} 23$ & 2 & 332 \\
\hline $\mathrm{M}$ & $\mathrm{r} 5$ & 1 & 335 \\
\hline $\mathrm{M}$ & $\mathrm{r} 23$ & 1 & 292 \\
\hline $\mathrm{N}$ & $\mathrm{r} 23$ & 3 & 183 \\
\hline $\mathrm{M}$ & $\mathrm{r} 23$ & 5 & 164 \\
\hline $\mathrm{N}$ & $\mathrm{r} 23$ & 4 & 164 \\
\hline $\mathrm{N}$ & $\mathrm{r} 12$ & 2 & 341 \\
\hline $\mathrm{T}$ & $\mathrm{r} 12$ & 2 & 168 \\
\hline $\mathrm{M}$ & $\mathrm{r} 5$ & 5 & 285 \\
\hline $\mathrm{M}$ & $\mathrm{r} 23$ & 4 & 228 \\
\hline
\end{tabular}

The experiment seeks to analyze the variable capacity and identify which shift has the highest demand. The summary for the capacity variable is shown in Table 4: 
Table 4. Result matrix.

\begin{tabular}{|c|c|}
\hline Count & 45 \\
\hline Average & 210.356 \\
\hline Median & 207.0 \\
\hline Variance & 7722.69 \\
\hline Standard deviation & 87.8788 \\
\hline Coeff. of variation & $41.7763 \%$ \\
\hline Minimum & 0 \\
\hline Maximum & 341.0 \\
\hline Range & 341.0 \\
\hline
\end{tabular}

The capacity variation is shown in Figure 6:

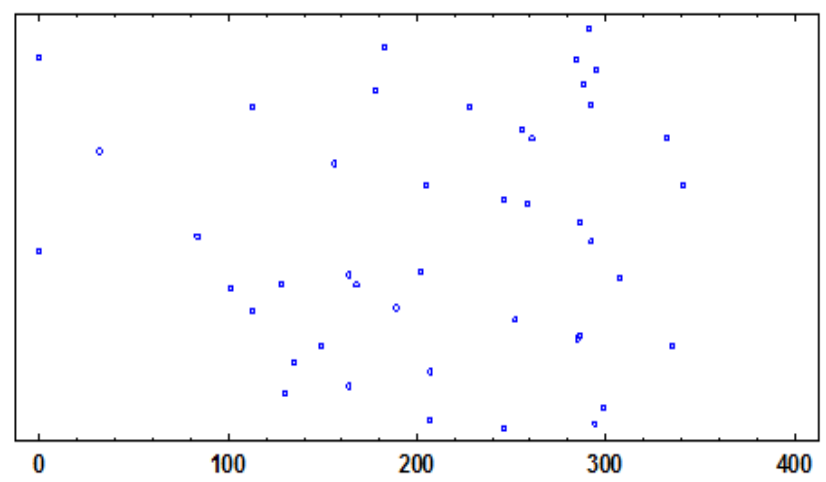

Fig. 6. Capacity variation.

In the figure 7 you can see in which shift there is more load:

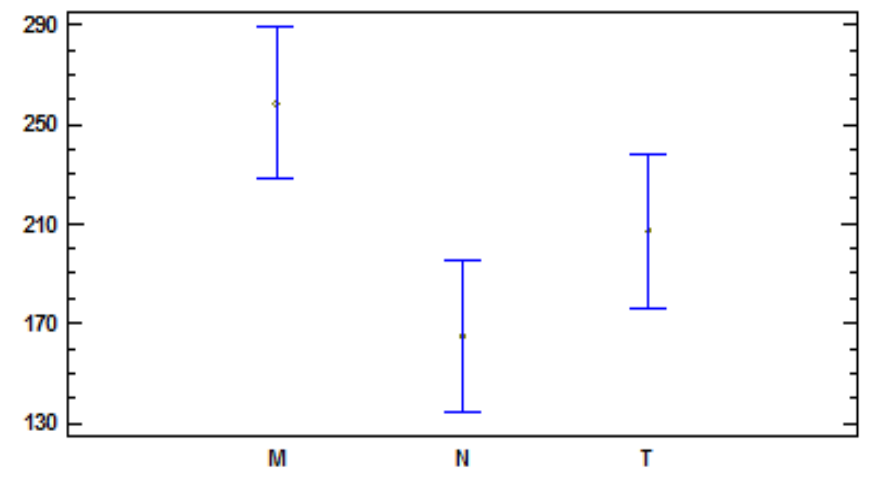

Fig. 7. Shifts. 
The graph shows that the lap where most charges are in the M, approximately 290, followed by $\mathrm{T}$, it is the turn of $12 \mathrm{pm}$ with 200 and less load is $\mathrm{N}$, that is to say that at $8 \mathrm{pm}$ people do not even require one unity.

The Figure 8 shows a larger capacity per shift, identifying $M$ with greater capacity for unit $r 5$ while for the same turn of unit r12 is the one that has less demand.

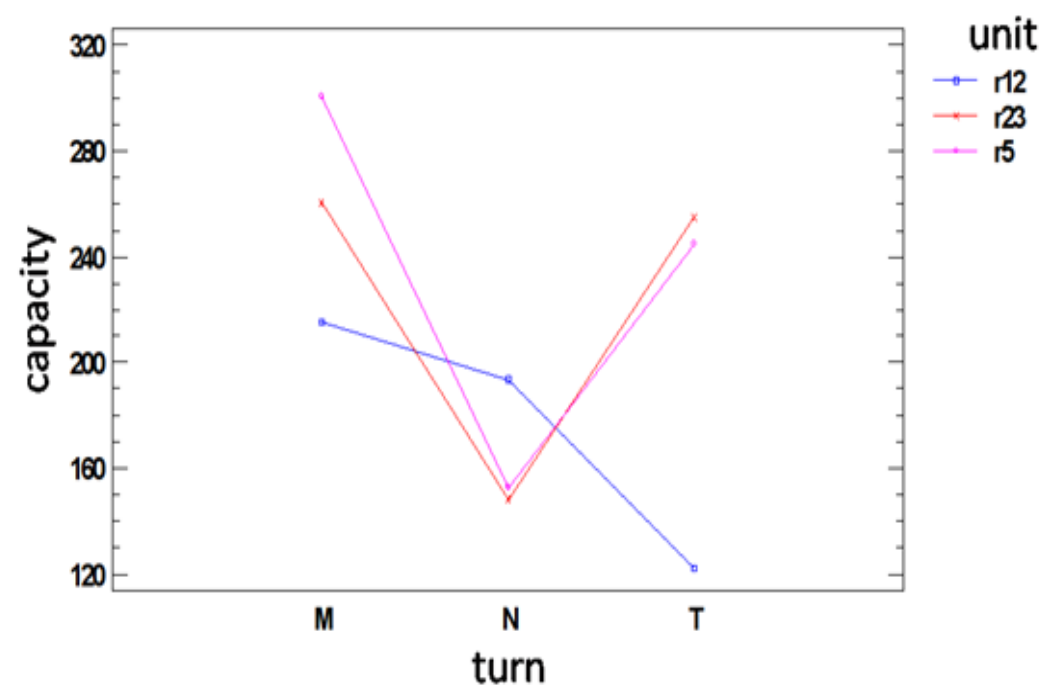

Fig. 8. Capabilities Per Turn.

We take the unit that has the most demand in the shift that more request and with greater capacity as case of application of the algorithm to determine an improvement. The case is for unit 5 , at time $\mathrm{M}$ on day 1 , i.e. unit 5 has more demand and therefore moves more people on Mondays; In the Table 5 the analysis can be appreciated:

Table 5. Result matrix.

\begin{tabular}{|c|c|c|c|}
\hline time & unit & day & capacity \\
\hline M & r5 & $\mathbf{1}$ & $\mathbf{3 3 5}$ \\
\hline M & r5 & 4 & 307 \\
\hline M & r5 & 2 & 288 \\
\hline M & r5 & 3 & 286 \\
\hline M & r5 & 5 & 285 \\
\hline
\end{tabular}

Points by passing the unit $\mathrm{M}$ are 12 , as shown in the Table 6: 
Table 6. Crossing points.

\begin{tabular}{|c|c|c|c|}
\hline Demand & Point & unit & time \\
\hline 13 & PAZTOLSA & 5 & $04 / 04 / 201608: 03$ \\
\hline 47 & 8DEJULIOLAPAZ & 5 & $04 / 04 / 201608: 10$ \\
\hline 10 & PQUE.SN.FCO & 5 & $04 / 04 / 201608: 13$ \\
\hline 27 & $\begin{array}{c}\text { ARENA } \\
\text { COLISEO(LUCHA) }\end{array}$ & 5 & $04 / 04 / 201608: 16$ \\
\hline 45 & $\begin{array}{c}\text { CRUZ VERDE RUIZ } \\
\text { SANCHEZ }\end{array}$ & 5 & $04 / 04 / 201608: 22$ \\
\hline 11 & VINOS LA PLAYA & 5 & $04 / 04 / 201608: 26$ \\
\hline 38 & $\begin{array}{c}\text { MERCADO DE LOS } \\
\text { OSOS }\end{array}$ & 5 & $04 / 04 / 201608: 32$ \\
\hline 41 & TEMPLOMALECON & 5 & $04 / 04 / 201608: 40$ \\
\hline 35 & SUBIDAMALECON & 5 & $04 / 04 / 201608: 43$ \\
\hline 9 & $\begin{array}{c}\text { STA,ROSALIA } \\
\text { MAELCON }\end{array}$ & 5 & $04 / 04 / 201608: 45$ \\
\hline 35 & $\begin{array}{c}\text { FARMACIA } \\
\text { GUADALAJARA }\end{array}$ & 5 & $04 / 04 / 201608: 47$ \\
\hline 24 & BASE214 & 5 & $04 / 04 / 201608: 51$ \\
\hline
\end{tabular}

The instance generated from the previous points is shown in Table 7:

Table 7. Instance IM12.

\begin{tabular}{|c|c|c|c|}
\hline number & $\mathbf{x}$ & $\mathbf{y}$ & demand \\
\hline 1 & 34 & 26 & 13 \\
\hline 2 & 38 & 16 & 47 \\
\hline 3 & 42 & 14 & 10 \\
\hline 4 & 64 & 26 & 27 \\
\hline 5 & 63 & 37 & 45 \\
\hline 6 & 72 & 42 & 11 \\
\hline 7 & 82 & 49 & 38 \\
\hline 8 & 94 & 50 & 41 \\
\hline 9 & 94 & 65 & 35 \\
\hline 10 & 93 & 72 & 9 \\
\hline 11 & 92 & 68 & 35 \\
\hline 12 & 95 & 73 & 24 \\
\hline
\end{tabular}

3 Apply the algorithm [12]. 


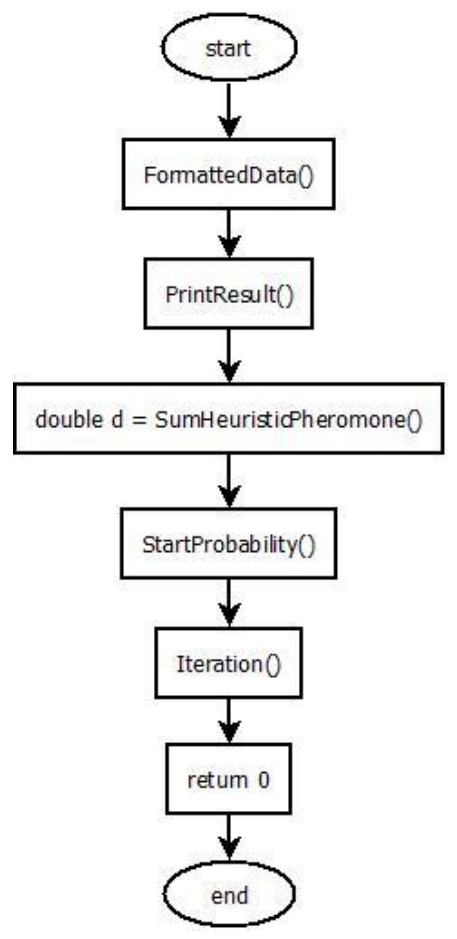

Fig. 9. The algorithm.

The main method consists of 5 functions in which processing algorithm is performed, as shown previously.

\section{$5 \quad$ Results}

The results derived from the execution of the algorithm with the instance IM12 are shown in the Table 8:

Table 8. IM12 results.

\begin{tabular}{|c|c|c|c|c|c|c|c|c|}
\hline cluster & cost & iterations & \multicolumn{5}{|c|}{ route } \\
\hline cluster-r5-clu1-3.vrp & 81 & 9 & 0 & 2 & 1 & 0 & & \\
\hline cluster-r5-clu2-4.vrp & 128 & 14 & 0 & 2 & 3 & 1 & 0 & \\
\hline cluster-r5-clu3-3.vrp & 145 & 100 & 0 & 1 & 2 & 0 & & \\
\hline cluster-r5-clu4-5.vrp & 170 & 8 & 0 & 1 & 4 & 2 & 3 & 0 \\
\hline
\end{tabular}


A cluster is generated by each array that creates the algorithm; It was decided to section in cluster to facilitate the analysis to a point more granular and not so general.

The cluster column contains the generated instances, the cost column is the result of the algorithm processing, the iterations column contains the cycles and finally the route column contains the suggested route.

The following images show the results of the execution

cluster-r5-clu1-3.vrp

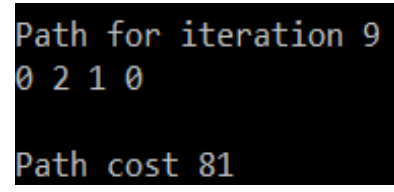

Fig. 10. Execution result cluster-r5-clu1-3.vrp.

cluster-r5-clu2-4.vrp

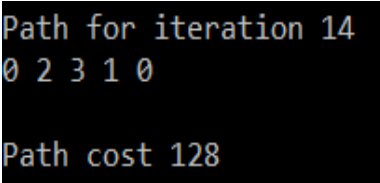

Fig. 11. Execution result cluster-r5-clu2-4.vrp.

cluster-r5-clu3-3.vrp

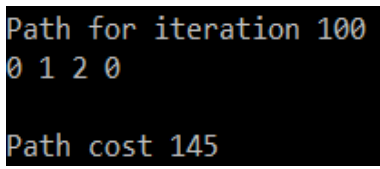

Fig. 12. Execution result cluster-r5-clu3-3.vrp.

\section{cluster-r5-clu4-5.vrp}

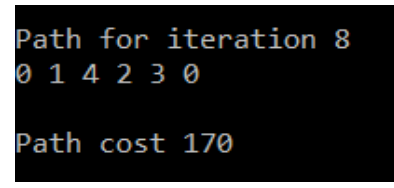

Fig. 13. Execution result cluster-r5-clu4-5.vrp. 


\section{Conclusions}

It is possible to improve the conditions under which units of public transport work by applying the ant colony algorithm.

The sequential ACO algorithm was implemented and the results were promising in terms of performance in response times and distribution of the units at different points and this suggests a reduction in the units needed to cover the sections.

It is possible to visualize the route geographically since the 37 control points of the route are identified and located.

This work shown the importance of real instances to solve specific problems supported by information technologies and metaheuristics.

\section{Future Work}

Future work is expected to apply parallelism using CUDA to further improve the algorithm and apply the present approach to MATLAB and Smart Cities.

\section{References}

1. SEMOV. Available at: http://semov.jalisco.gob.mx (2016)

2. Fox, B., Xiang, W., Lee, H. P.: Industrial applications of the ant colony optimization algorithm. The International Journal of Advanced Manufacturing Technology, 31(7), pp. 805-814 (2006)

3. Bolufé-Röhler, A., Otero-Pereira, J. M., Fiol-González, S.: Traffic Flow Estimation Using Ant Colony Optimization Algorithms. Computación y Sistemas, pp. 37-50 (2014)

4. Grau, I., Nápoles, G.: Mutating HIV Protease Protein Using Ant Colony Optimization and Fuzzy Cognitive Maps: Drug Susceptibility Analysis. Computación y Sistemas, pp. 51-63 (2014)

5. Rivero, J. C.: Using the ACO algorithm for path searches in social networks.

6. UC3M. Available at: http://portal.uc3m.es/portal/page/portal/actualidad_cientifica/noticias/ buscador_redes_sociales (2016)

7. MIDACO-SOLVER. Available at: http://www.midaco-solver.com (2015)

8. Bullnheimer, B., Hartl, R., Strauss, C.: An improved Ant System algorithm for the Vehicle Routing Problem. Annals of Operations Research, 89, pp. 319-328 (1999)

9. NEO. Available at: http://neo.lcc.uma.es/vrp/vrp-flavors (2015)

10. Blocho, M., Czech, Z. J.: Parallel Processing and Applied Mathematics. 9th International Conference, PPAM 2011, Torun, Poland (2012)

11. Gutiérrez-Pulido, H.: Diez problemas de la población de Jalisco: una perspectiva sociodemográfica. Gobierno de Jalisco (2010)

12. Md. Rabiul Islam. Available at: https://github.com/rabiulhasibul/ACO-for-CVRP (2016) 